Brit. F. vener. Dis. (1968), 44, 109.

\title{
RECOVERY OF SPIROCHAETES IN THE MONKEY BY PASSIVE TRANSFER FROM HUMAN LATE SERO-NEGATIVE SYPHILIS* $†$
}

\author{
BY \\ J. LAWTON SMITH AND CHARLES W. ISRAEL \\ From the Department of Ophthalmology, University of Miami School of Medicine, Miami, Florida, U.S.A.
}

The discovery of treponemes, staining with fluorescein-tagged anti-Treponema pallidum globulin in various tissues of patients with late sero-negative ocular and neurosyphilis, was reported by Smith and Israel (1967a). The purpose of this paper is to document the results of passive transfer of these spirochaetes to the experimental primate.

Although notes on the following case were included in a previous report (Smith and Israel, 1967a), the recovery of treponemes from the patient's aqueous humour, cerebrospinal fluid, and liver, and the results of passive transfer of these treponemes from both cerebrospinal fluid and aqueous humour to two squirrel monkeys, were thought sufficiently important to warrant a more detailed consideration of the clinical data. An additional fact of importance was that the patient's serum showed false negative reactions to both the TPI and FTA-ABS tests.

\section{Case Report}

This 77-year-old right-handed white male was first seen on September 16,1966, through the courtesy of Dr Leonard Berg. The patient complained of difficulty with vision and of sensory loss in the extremities. He had been well until 1953 when a painful burning sensation began in the feet. He was told then that he had "peripheral neuritis". In 1956 the gradual onset of a high-tone deafness began in the left ear, and later involved the right. He was started on cortisone therapy in 1957 which partially relieved the discomfort in the feet, but generalized weakness followed. In 1958 he developed a right ptosis and in 1959 he began to lose sensation in the fingers of the right hand.

He was first admitted to Jackson Memorial Hospital on September 18,1966, and the following notes were recorded by Drs Keedy and von Storch at that time. Ptosis and meiosis were present on the right; the right

* Received for publication July 5, 1967.

† This investigation was supported in part by Public Health Service research grants CC 00144-02 and NBI-EP 1 R1-NB, and fellowship IF1LNB 1633-01 VSN, from the National Institute of Neurological Diseases and Blindness. pupil failed to react to light, but responded rapidly to accommodation; the left pupil was larger and reacted poorly to light but rapidly to accommodation. All arm and leg reflexes were absent. Position and vibration sense were depressed throughout, and deep pain sensation was decreased at the left ankle. Pin and touch sensation were absent in a sock distribution, more at the left ankle than the right. Touch was decreased in the fingers of the right hand. The abdominal reflexes were present. Gait and coordination were normal. The soles of his feet were hypersensitive, but the plantar responses were flexor.

Laboratory Studies The blood picture and urinary findings were normal. A 2-hour postprandial blood glucose value was $76 \mathrm{mg}$. $/ 100 \mathrm{ml}$.

Lumbar puncture on September 20,1960, revealed a clear colourless fluid with one monocyte and three erythrocytes per c.mm.; VDRL test negative; total protein level $107 \mathrm{mg} . / 100 \mathrm{ml}$; colloidal gold curve 5554332100.

Skull and chest $x$ rays and an electro-encephalogram were within normal limits.

It was noted that a history of syphilis was denied but the patient had admitted having severe gonorrhoea as a young man. The diagnosis at discharge was peripheral neuropathy and myelopathy of the brain stem of unknown cause.

Slow progression of the neurological complaints continued after discharge. Between 1963 and 1964 hepatosplenomegaly was detected, and the question of dysproteinaemia was raised. Intermittent steroid therapy was continued, with the patient receiving a single weekly dose of $100 \mathrm{mg}$. prednisone. Because of intermittent slight blurring of vision and occasional transient diplopia, he saw his ophthalmologist, who noted a Horner's syndrome on the right, and referred him for neuro-ophthalmological consultation.

Examination (September 16, 1966) He was a thin, elderly man wearing binaural hearing aids on his glasses. He walked with great care. He appeared reasonably alert mentally, but his wife volunteered that he had developed some memory loss during the past few months. Corrected 
visual acuity was $20 / 25$ in both eyes. External eye examination revealed ptosis and meiosis on the right, and the pupillary reactions were as originally noted with much crisper reactions to accommodation than to light (Figs 1 to 3). A cocaine test gave results consistent with a right oculo-sympathetic paresis (Fig. 4). There was a very slight limitation of movement of the right eye in all directions of gaze, consistent with a partial right external ophthalmoplegia. Biomicroscopy revealed some iris sphincter atrophy in both eyes, and ophthalmoscopy revealed only borderline disc pallor bilaterally. Applanation showed that the ocular tensions were normal, and quantitative perimetry showed only a minimal concentric contraction of the visual fields.

Because of a strong clinical suspicion of tabes dorsalis, the patient was re-admitted to hospital. The findings were essentially those noted in 1960 , although progression had occurred. Vital signs were normal. The liver and spleen were palpable three and two fingerbreadths below the costal margin, respectively.

Laboratory Studies The patient was anaemic $(\mathrm{Hb}$ 8 to $10 \mathrm{~g} . / 100 \mathrm{ml}$.), and azotaemic (blood urea nitrogen 55 to $62 \mathrm{mg}$. $/ 100 \mathrm{ml}$.), serum calciumlevel $13 \cdot 1 \mathrm{mg} . / 100 \mathrm{ml}$. The blood VDRL test was non-reactive.

Lumbar puncture revealed a normal opening pressure; cerebrospinal fluid clear and colourless with two monocytes per c.mm.; VDRL test negative; total protein level $87 \mathrm{mg} . / 100 \mathrm{ml}$.; slight midzonal colloidal gold curve.

It was of interest that a serum FTA-ABS test was non-reactive in this case; another blood specimen was submitted to the Venereal Disease Research Laboratory in Atlanta and the VDRL, TPI, and FTA-ABS tests gave negative results.

On September 19, 1966, a paracentesis of the anterior chamber of the right eye was performed; a few drops of aqueous humour were removed for diagnostic study and

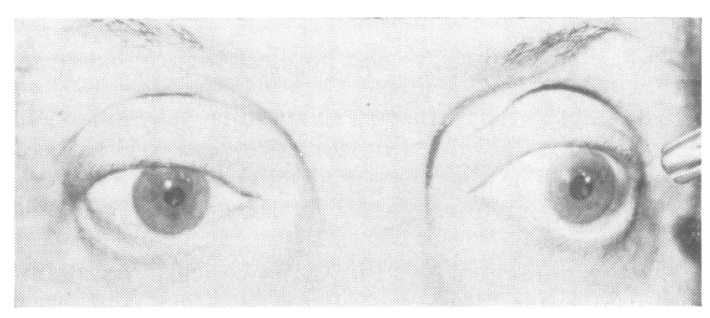

Fig. 1.-Patient fixing at distance, with light on left eye.

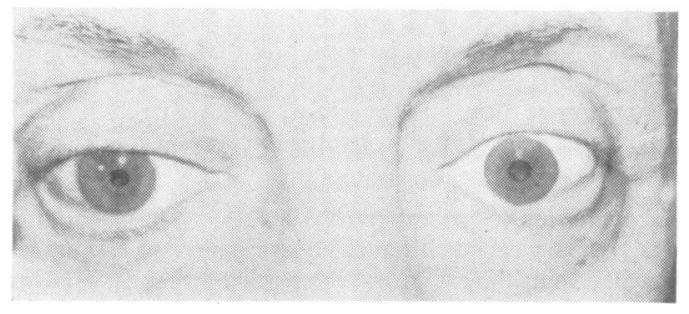

FIG. 3.-Patient fixing at near, with light on right eye. Note better responses of pupils to near than to light (compare with Fig. 2). darkfield examination revealed two motile spirochaetes (Fig. 5). It should be noted that this was clinically a white and quiet eye at the time, with no cells or flare present on biomicroscopy before the tap.

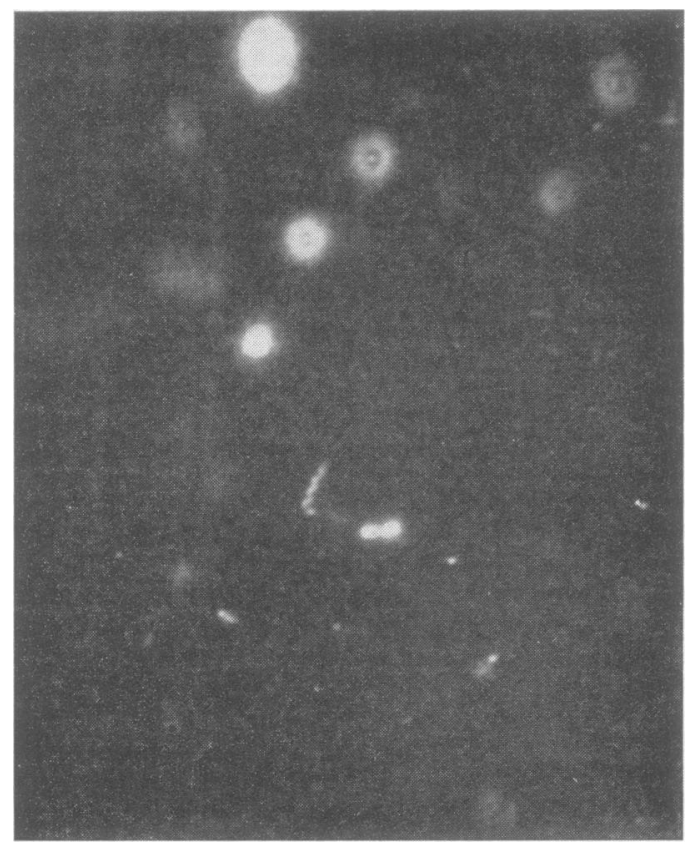

FIG. 5.-Aqueous humour of right eye of patient on darkfield examination September 20,1966. This aqueous was inoculated into squirrel monkey 920 . $\times 66$.

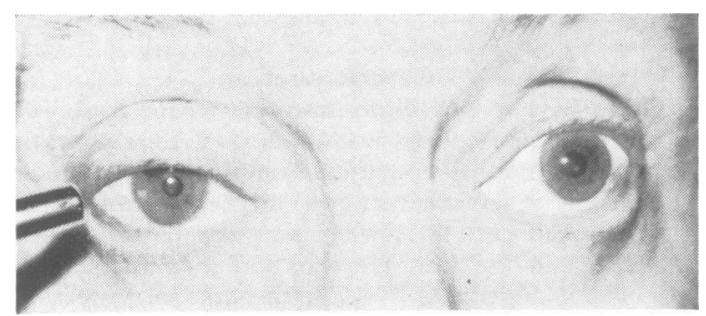

FIG. 2.-Patient fixing at distance, with light on right eye.

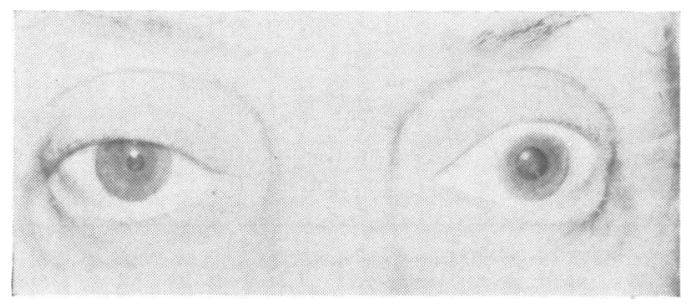

FIG. 4.-Patient after instillation of two drops of cocaine into each eye. Note right Horner's syndrome. 


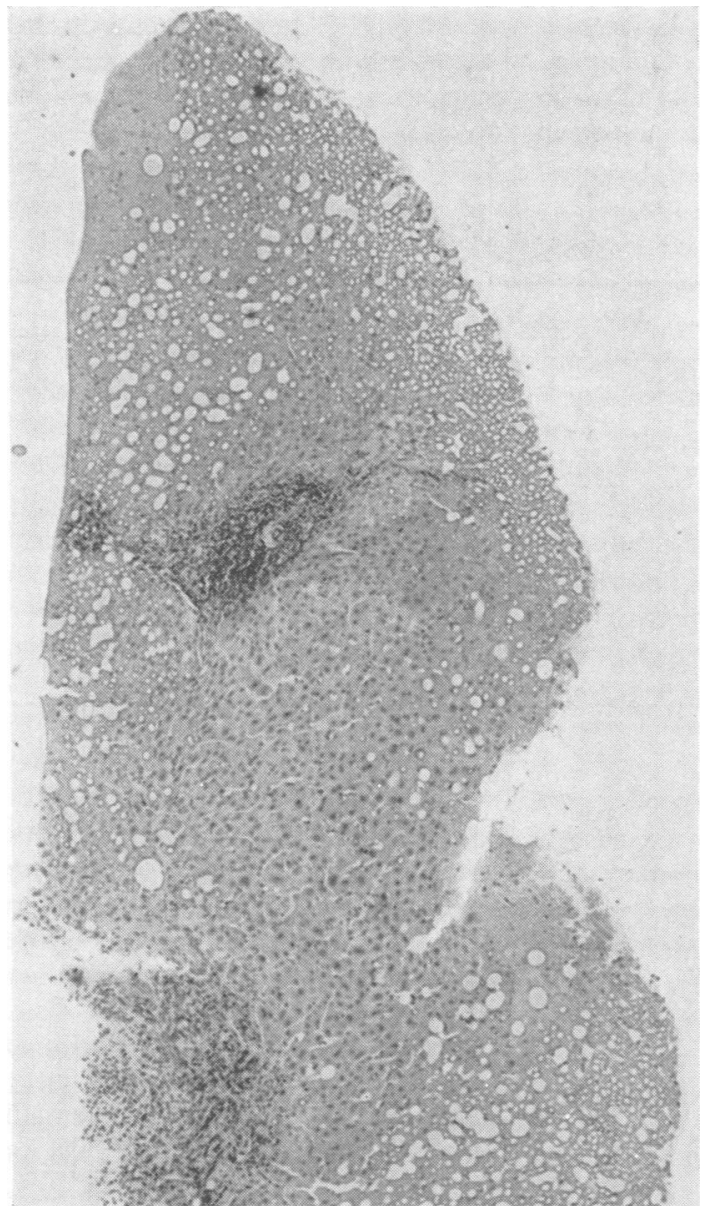

FIG. 6.-Photomicrograph of liver biopsy specimen from patient Note focal collections of lymphocytes. Haematoxylin and eosin.

Two days later, a needle biopsy of the liver was performed. One part was sent to the Pathology Department, which reported focal collections of lymphocytes, but no definite tissue diagnosis was made (Figs 6 and 7).

An amyloid stain of the liver was negative. Another part of the liver biopsy was immediately frozen and cryostat sections 4 microns thick were cut for darkfield and fluorescent antibody stains (Wells and Smith, 1967a, b). Darkfield examination revealed large numbers of spirochaetes in the liver, and these stained brilliantly with fluorescein-tagged anti-Treponema pallidum globulin (Fig. 8).

Subsequent staining of the biopsy specimen with the Krajian silver method revealed four or five spirochaetes, but, as has consistently been our experience in the past, the organisms were much more easily detected and were found in much larger numbers with the fluorescent antibody techique than with the silver stain.

Treatment After the inoculation of two squirrel monkeys with material from this patient, he was treated with a total of 18 mega units procaine penicillin $G$ before

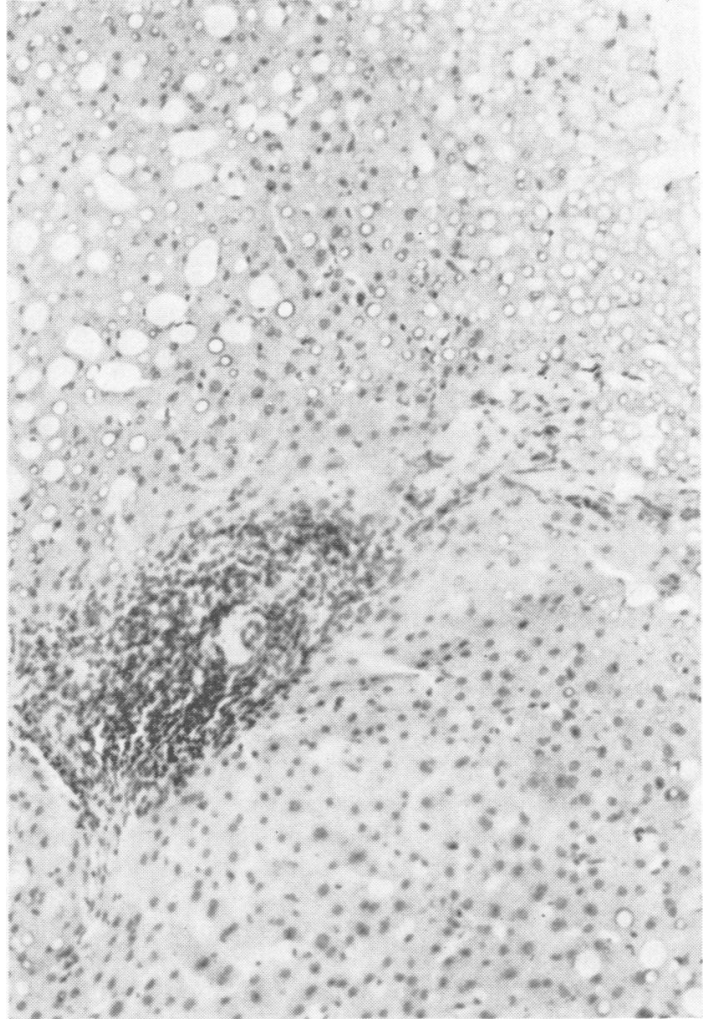

FIG. 7.-Higher-power photomicrograph of liver biopsy from patient. Haematoxylin and eosin.

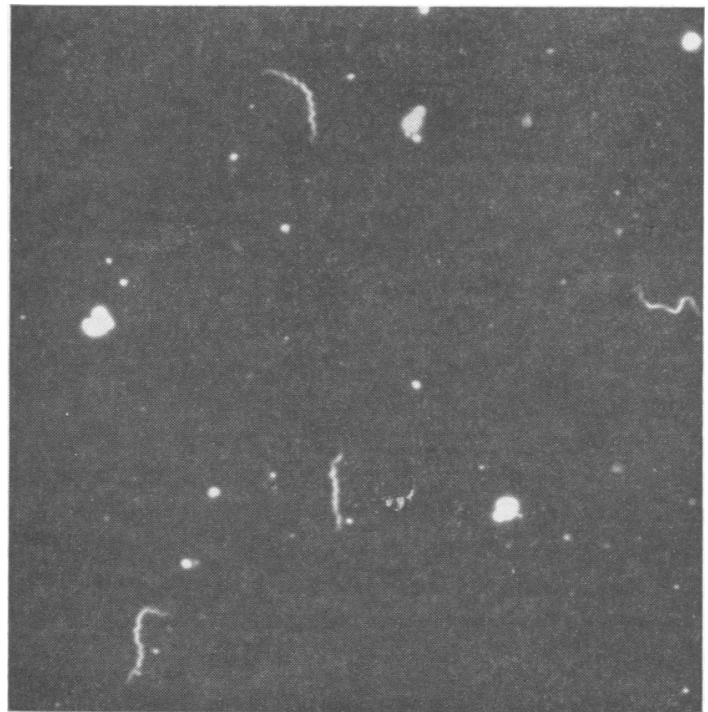

FIG. 8.-Darkfield photomicrograph of liver biopsy shown in Figs 6 and 7. Hundreds of spirochaetes were found and the treponemes stained with fluorescein-tagged anti-Treponema pallidum globulin on ultraviolet microscopy. 
leaving hospital. Because we had previously found treponemes in the aqueous humour and various tissues of other patients who had received large doses of systemic penicillin therapy (Smith and Israel, 1967b), this patient was given a weekly injection of 2.4 mega units benzathine penicillin by his physician for the next 4 months. The patient appeared to improve slightly for a short time, but died quietly at home several months later.

Comment This 77-year-old man presented clinical findings so typical of parenchymatous neurosyphilis that this was the first diagnosis considered by numerous physicians who had seen him during the past 14 years of his illness. He had anisocoria, marked light-near dissociation of the pupils, iris atrophy, bilateral hearing loss, and sensory loss in the extremities, and admitted to a history of venereal infection as a young man. However, repeated negative results to serum reagin tests had been obtained in several hospitals, and three non-reactive cerebrospinal fluid VDRL tests had also been obtained in the past 10 years. There was an elevation of the spinal fluid total proteins, with some colloidal gold curve changes, but pleocytosis had not been present on any occasion. The finding of hepatosplenomegaly and anaemia had raised the question of dysproteinaemia in this patient, but the electrophoretic pattern of serum proteins was within normal limits, and a liver biopsy showed a negative amyloid stain. Despite non-reactive VDRL, TPI, and FTA-ABS tests on peripheral blood, spirochaetes were found in the aqueous humour and cerebrospinal fluid and also in the liver biopsy specimen when studied with the fluorescent antibody stain.

\section{Passive Transfer Experiments}

Two squirrel monkeys (Saimiri sciurea) were inoculated with fluids obtained from this patient. The animals were housed in separate cages; they received no treatment whatever, and were followed with serial clinical and serological examinations, in the manner previously reported (Taylor, Smith, and Singer, 1965; Smith, Singer, Reynolds, Moore, Yobs, and Clark, 1965; Wells and Smith, 1967c).

\section{Squirrel Monkey WJP}

This monkey was inoculated on September 16, 1966 , with three intradermal injections $(0.1 \mathrm{ml}$. each) of centrifuged cerebrospinal fluid obtained from the patient. No more than 10 to 15 minutes elapsed between the lumbar puncture and the injection of the freshly centrifuged fluid into three abdominal skin sites. Examinations were negative until December 26, 1966, when a question was raised as to superficial pigmentation on the animal's abdomen. On January 26,1967 , a minute superficial nodule was palpable on the lower abdomen, and on February 9, 1967, there appeared to be a minimal induration at this site. This finding was so slight, however, that the examiner was not certain whether a lesion was present. On April 6, 1967, careful examination of the eyes and abdomen revealed no abnormalities whatsoever. The serological reactions are shown in Table I.

TABLE I

SEROLOGICAL STUDIES IN SQUIRREL MONKEY WJP

\begin{tabular}{|c|c|c|c|}
\hline Date & VDRL & FTA-ABS & TPI \\
\hline $\begin{array}{l}11.3 .66 \\
11.8 .66 \\
16.9 .66 \\
5.10 .66 \\
18.11 .66 \\
27.12 .66 \\
2.2 .67 \\
23.3 .67 \\
6.4 .67 \\
21.4 .67 \\
14.7 .67 \\
27.7 .67 \\
27.10 .67 \\
16.1 .68 \\
29.2 .68 \\
8.5 .68\end{array}$ & \begin{tabular}{c|} 
NR \\
NR \\
Date of inocul \\
Very WR \\
NR \\
NR \\
NR \\
NR \\
Paracentesis of \\
NR \\
NR \\
NR \\
NR \\
NR \\
R(1)
\end{tabular} & $\begin{array}{c}\mathbf{N R} \\
\text { NR } \\
\text { ation with patien } \\
\text { NR } \\
\mathbf{N R} \\
\mathbf{N R} \\
\pm \mathbf{N R} \\
\pm \mathbf{N R} \\
\text { right eye = spirc } \\
\mathbf{N R} \\
\pm \mathbf{N R} \\
\mathbf{R}+ \\
\mathbf{N R} \\
\mathbf{N R} \\
\mathbf{N R} \\
\pm \mathbf{N R}\end{array}$ & $\left.\right|_{\text {ochaetes }} ^{\text {tt's spinal fluid }}$ \\
\hline
\end{tabular}

Because of the equivocal FTA-ABS tests in this monkey (see Table I), and because, in cases with this serological pattern, we had sometimes found treponemes in clinically quiet eyes (Smith, 1965; Smith, 1967), a paracentesis of the anterior chamber was performed on the right eye on April 6, 1967, i.e. 7 months after intradermal inoculation. Darkfield examination of the aqueous fluid revealed large numbers of motile spirochaetes, which stained definitely with fluorescein-tagged anti-Treponema pallidum globulin (Figs 9 to 11, opposite). In July, 1967 , this monkey developed a crusted lesion on the base of the nose. Biopsy of this lesion was darkfield positive.

\section{Squirrel Monkey 920}

This monkey was inoculated on September 20, 1966 , with $0.015 \mathrm{ml}$. uncentrifuged fresh aqueous humour removed from the right eye of the patient reported above. The fluid was injected intradermally into the left upper quadrant of the abdomen within 5 minutes of the paracentesis. Examination one month later revealed no lesions, but on November 17, 1966, an equivocal spot was seen at the injection site. On December 26, 1966, a small skin biopsy was performed at the site of original inoculation. This was considered extremely suspicious on darkfield examination. Subsequent examinations showed no definite skin lesions and the eyes remained normal for several months. The serological responses are shown in Table II (opposite). On April 6, 1967, i.e. 7 months after intradermal inoculation of this 


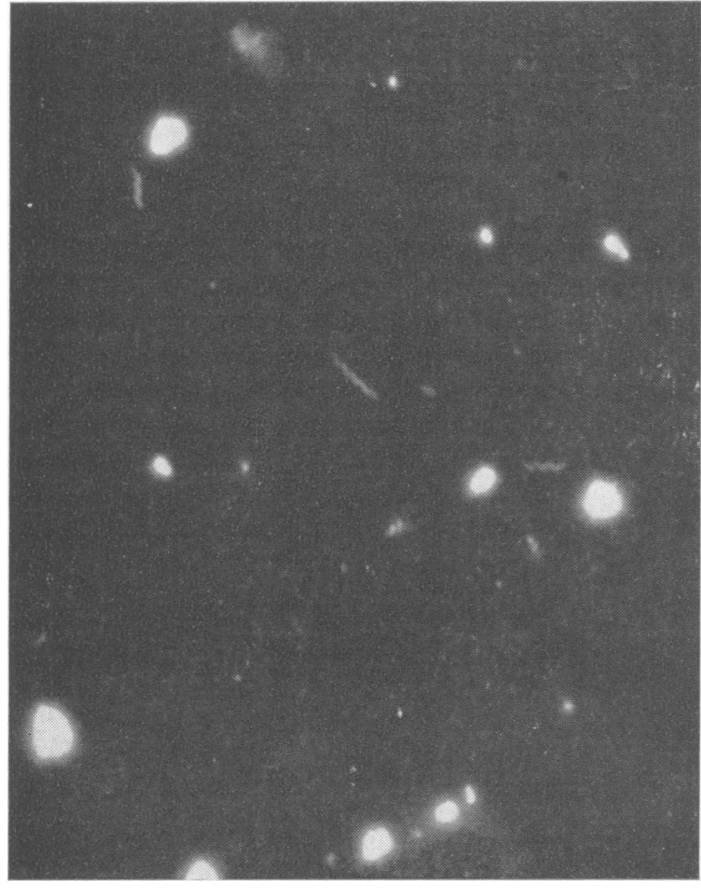

FIG. 9.-Darkfield photomicrograph of aqueous humour from squirrel monkey WJP, inoculated intradermally 7 months previously with cerebrospinal fluid from the patient seen in Figs 1 to 8 .

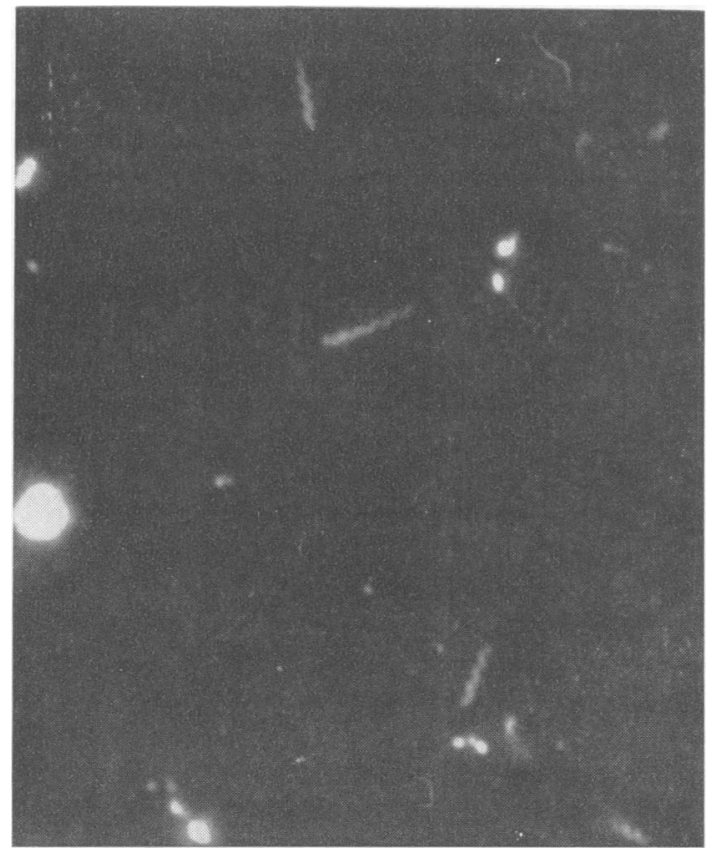

FIG. 10.-Another darkfield photomicrograph of aqueous humour of squirrel monkey WJP, showing treponemes recovered by passive transfer from man.

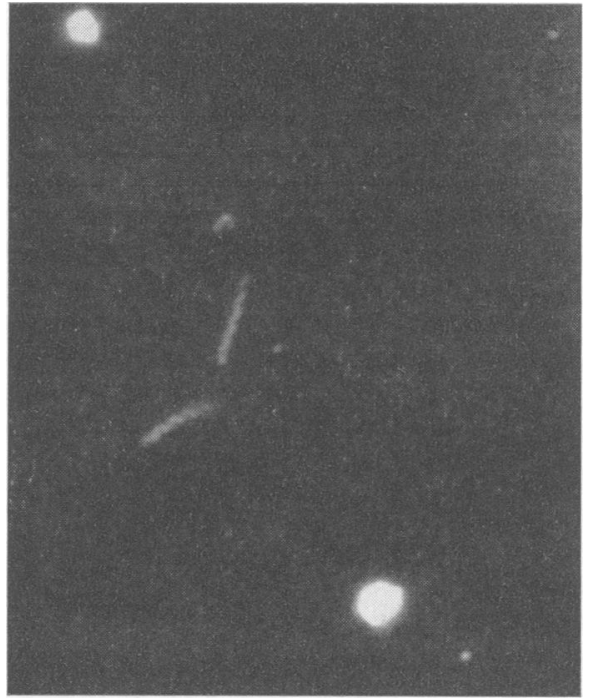

FIG. 11.-Another field showing spirochaetes from aqueous humour of squirrel monkey recovered after passive transfer to abdominal skin of cerebrospinal fluid from man.

\section{TABLE II}

SEROLOGICAL STUDIES IN SOUIRREL MONKEY 920 FROM SEPTEMBER, 1966, TO FEBRUARY, 1968

\begin{tabular}{|c|c|c|c|}
\hline Date & VDRL & FTA-ABS & TPI \\
\hline $\begin{array}{l}20.9 .66 \\
\text { After blood was }\end{array}$ & drawn, the monk & $\begin{array}{c}\text { NR } \\
\text { key was inocula }\end{array}$ & ed intradermally \\
\hline $\begin{array}{l}\text { 5.10.66 } \\
18.11 .66 \\
26.12 .66 \text { Bi วpsy o }\end{array}$ & $\mid \begin{array}{c}\text { with } \\
\text { NR } \\
\text { f inoculation site }\end{array}$ & $\begin{array}{l}\text { ueous numour } \\
\pm N R \\
\text { NR } \\
\text { revealed very su }\end{array}$ & \\
\hline $\begin{array}{l}24.2 .67 \\
23.3 .67 \\
21.4 .67 \\
6.6 .67 \\
27.7 .67 \\
1.9 .67 \\
27.9 .67 \\
29.2 .68\end{array}$ & \begin{tabular}{|l|} 
sy later found to \\
NR \\
NR \\
NR \\
NR \\
NR \\
qns \\
NR \\
NR
\end{tabular} & $\begin{array}{c}\text { be FA-positive } \\
\text { NR } \\
\text { NR } \\
\text { NR } \\
\text { NR } \\
\text { NR } \\
\text { NR } \\
+N R \\
\text { NR }\end{array}$ & $\begin{array}{l}\mathrm{Ac} \\
\mathrm{R} \\
\mathrm{Ac}\end{array}$ \\
\hline
\end{tabular}

$\mathrm{NR}=$ non-reactive.

qn $3=$ insufficient quantity.

Ac $=$ anticomplementary $\mathbf{R}=$ reactive.

monkey with aqueous humour from the patient, a paracentesis was done on the anterior chamber of its right eye. Darkfield examination of this aqueous was negative. This was a not unexpected result, since the animal had been given a much smaller inoculum, having received $0.015 \mathrm{ml}$. uncentrifuged aqueous humour, whereas squirrel monkey WJP had received a total of $0.3 \mathrm{ml}$. centrifuged cerebrospinal fluid, probably containing several hundred times as many spirochaetes. However, because treponemes had been found in the first monkey the frozen tissue of the skin biopsy taken 3 months after inoculation was removed from the freezer, cut on the cryostat in four 
micron sections, and stained by the fluorescent antibody (FA) method. Definite spirochaetes were found in this skin biopsy, and these stained with fluorescein-tagged anti-Treponema pallidum globulin.

\section{Discussion}

A study of experimental sero-negative ocular and neurosyphilis in rabbits and in two primate species has been in progress at the Department of Ophthalmology, University of Miami School of Medicine, during the past 4 years. Fluorescent antibody techniques have been found to be the best methods now available to corroborate a diagnosis of syphilis. These have included the FTA-ABS test on blood, and the FTA stain for smears and frozen tissue sections. During this study in experimental animals, about 2 years ago, spirochaetes were sometimes seen in the aqueous humour of animal eyes showing no biomicroscopic abnormality whatever. After confirmation of these findings in October, 1966, a cautious investigation was begun in cases of patients with clinical evidences of late ocular and neurosyphilis. Suffice it to say that treponemes have now been found in aqueous humour, cerebrospinal fluid, liver, lymph node, superficial temporal artery, and aorta in patients with late sero-negative syphilis. The organisms have been found in clinically normal cerebrospinal fluids (showing no abnormalities in cell count, total protein, colloidal gold curve, or reagin tests) from patients who have had large doses of penicillin therapy in the past.

The present paper documents the recovery of spirochaetes by passive transfer to primates from cerebrospinal fluid and aqueous humour from a patient with clinical signs of late syphilis, but in whom three serological tests for syphilis (VDRL, TPI, FTA-ABS) were non-reactive, although repeated at two different laboratories.

Certain points merit mention here. It may be asked why the passive transfer studies were done in primates, in which the diagnosis of syphilis may at times be difficult, rather than in the rabbit, which has been the species most often used in experimental syphilis for over 50 years. This is because rabbits are known to harbour an endemic venereal disease known as benign venereal spirochaetosis, due to Treponema cuniculi, an organism which is morphologically, serologically, and pathologically indistinguishable from Treponema pallidum (Smith and Pesetsky, 1967). Indeed, one out of four normal rabbits purchased on the open market will show a reactive or weakly reactive VDRL serum test, even when no clinical signs of disease are present (Pannu, Rosenberg, Israel, and Smith, 1967). Therefore, if one had inoculated a rabbit with a specimen from a patient, and had later demonstrated the presence of spirochaetes, it would have been difficult to decide whether the organism was Treponema cuniculi.

The development of a cutaneous lesion on the base of the nose of squirrel monkey WJP 9 months after inoculation of the animal was of great interest. This lesion was darkfield positive. The importance of keeping animals inoculated from patients with late syphilis under observation for protracted periods of time is also seen in this experiment. A reactive TPI test was first obtained at 12 and 16 months after inoculation, respectively, in the two monkeys used in this study. The VDRL test appeared to be undergoing sero-conversion only at $1 \frac{1}{2}$ years after inoculation in squirrel monkey WJP. In this laboratory owl monkeys and squirrel monkeys inoculated with large numbers of virulent Nichols strain Treponema pallidum organisms by various routes have been found to show a clinical course nearly identical to that frequently seen in late syphilis in man. Indeed, it often requires 2 to 3 years of observation in these species before serum VDRL conversion may occur, if this happens at all, despite prior inoculation with over 200,000 virulent Nichols strain Treponema pallidum organisms. Furthermore, similar results were noted in both Rhesus and African green monkeys by Turner and Hollander (1957). The importance of the discovery of spirochaetes in late sero-negative syphilis in man, and of their transmission to experimental animals by passive transfer, is evident and merits prompt and major re-investigation of the late stages of this disease.

\section{Summary}

Spirochaetes with the morphology of Treponema pallidum, which are motile on darkfield examination and which stain with fluorescein-tagged antiTreponema pallidum globulin when viewed with ultraviolet microscopy, have been found in patients with clinical signs of late sero-negative ocular and neurosyphilis. This study documents the recovery of spirochaetes by passive transfer to two monkeys using cerebrospinal fluid and aqueous humour taken from a patient with late syphilis whose serum demonstrated a false negative FTA-ABS test. The serum FTA-ABS test, although by far the best serological test for syphilis now available, is not infallible, and cannot replace meticulous historytaking and physical examination of the patient.

\section{REFERENCES}

Pannu, J. S., Rosenberg, M. A., Israel, C. W., and Smith, J. L. (1967). Brit. F. vener. Dis., 43, 114. 
Smith, J. L. (1965). In "Neuro-ophthalmology. Symposium of the University of Miami and the BascomPalmer Eye Institute", ed. J. L. Smith, vol. 2, pp. 1-43. Mosby, St. Louis. (1967). "Seronegative Ocular and Neurosyphilis". Candidate's thesis, American Ophthalmological Society, submitted in 1967.

_ and Israel, C. W. (1967a). F. Amer. med. Ass., 199, 980.

(1967b). Arch. Opthal. (Chicago), 77, 474. and Pesetsky, B. R. (1967). Brit. F. vener. Dis., 43, 117.

—, Singer, J. A., Reynolds, D. H., Moore, M. B., Jr., Yobs, A. R., and Clark, J. W., Jr. (1965). Ibid., 41, 15.

Taylor, W. H., Smith, J. L., and Singer, J. A. (1965). Amer. F. Ophthal., 60, 1093.

Turner, T. B., and Hollander, D. H. (1957). "Biology of the Treponematoses". World Health Organization, Monogr. Ser. No. 35, p. 41. WHO, Geneva.

Wells, J. A., and Smith, J. L. (1967a). Amer.F. Ophthal., 63, 410 .

(1967b). In "Neuro-ophthalmology; Symposium of the University of Miami and the BascomPalmer Eye Institute", ed. J. Lawton Smith, vol. 3, pp. 274-293. Mosby, St. Louis.

_— (1967c). Brit. F. vener. Dis., 43, 10.
La récuperation des spirochètes chez le singe après passage passif de l'humain atteint de syphilis tardive séro-négative

\section{RÉSUMÉ}

Les spirochètes ayant la morphologie du Treponema pallidum qui sont mobiles à l'examen sur fond noir et qui se colorent au "fluorescein-tagged anti-Treponema pallidum globulin" à l'examen au microscope ultraviolet, ont été trouvés chez les patients donnant des signes cliniques de syphilis nerveuse et oculaire tardives à reaction séro-negative. Cette étude documente la récuperation des spirochètes après passage passif chez deux singes en employant le liquide céphalo-rachidien et l'humeur aqueuse pris d'un malade atteint de syphilis tardive et dont le sérum avait donné une réaction pseudonégative au test FTA-ABS. Le test FTA-ABS fait avec le sérum, quoique étant le meilleur test sérologique pour la syphilis qui soit disponible de nos jours n'est pas infaillible, et ne peut remplacer un examen clinique minutieux et un historique méticuleux obtenu de sujet. 